\title{
LEVANTAMENTO DE ESPÉCIES DE ABELHAS SEM FERRÃO EM UNIDADES DE CONSERVAÇÃO NO CORREDOR CENTRAL DA MATA ATLÂNTICA NA REGIÃO DE PORTO SEGURO,BA
}

\author{
AUTOR: ARIANY SANTOS ALMEIDA \\ CO-AUTOR/ORIENTADOR: OLIVIA MARIA PEREIRA DUARTE
}

Resumo: Os Meliponíneos são encontrados em regiões tropicais e subtropicais. No Brasil, as abelhas nativas sem ferrão são distribuídas em todos os seus biomas. As abelhas contribuem na reprodução das plantas com o processo de polinização onde o grão de pólen é levado até o gameta feminino da planta, promovendo a biodiversidade vegetal e nativa do Brasil. A Mata Atlântica é um dos biomas brasileiros mais ricos em biodiversidade e o mais ameaçado. Com os problemas antrópicos como desmatamento, uso intensivo de agroquímicos, os meliponíneos estão sendo ameaçados, principalmente por perda de habitat gerando implicações na manutenção ecológica da Mata Atlântica. Com isso, o trabalho tem como objetivo realizar um levantamento de espécies de abelhas sem ferrão em Unidades de Conservação no Corredor Central da Mata Atlântica, ampliando o conhecimento sobre o grupo. O estudo foi realizado na Reserva Particular do Patrimônio Natural - RPPN Estação Veracel, que é a segunda maior reserva privada na Mata Atlântica com extensão de 6.069 hectares. Os trabalhos em campo foram realizados entre setembro de 2019 a fevereiro de 2020 . Onde foi realizada a busca por ninhos das abelhas, as amostras foram coletadas com rede entomológica na entrada dos ninhos e em forrageio em quatro blocos da RPPNEVC. As amostras foram armazenadas em potes com etanol, montados em alfinetes entomológicos e guardados no Laboratório Interdisciplinar da UFSB e na Coleção de Zoologia. Foram encontrados 6 gêneros de abelhas sem ferrão e 7 espécies: Trigona braueri (Friese,1900), Trigona spinipes (Fabricius, 1793), Paratrigona spp, Tetragonisca angustula (Latreille, 1811), Tetragona clavipes (Fabricius, 1804), Melipona rufiventris (Illiger, 1806) e Frieseomelitta spp, onde desses gêneros foram identificados 2 ninhos. Dessa forma, a realização do trabalho produziu informações que servirão como base para estudos adicionais já que não haviam dados de registro de ocorrência das espécies de abelhas sem ferrão da região e também serão úteis na atualização do Plano de Manejo da Unidade.

Palavras-chave: Meliponíneos1, Polinização2, Mata Atlântica3, Conservação4. 